\title{
Superphénix to become a plutonium 'furnace'
}

Paris. France is to reorientate its fast-breeder reactor programme - the last in Europe towards burning-up plutonium generated from waste and dismantled weapons.

According to Jacques Bouchard, director of nuclear reactors at the French Atomic Energy Commission (CEA), the move has been prompted by the difficulty of justifying new fast-breeders when few conventional reactors are being built. The slowdown has also postponed the predicted uranium shortage that would have created a need for reactors that breed their own fuel, he says.

Similar considerations have already caused the United Kingdom and Germany to withdraw from the European Fast Breeder (EFR) programme late last year (see Nature 360, 93 \& 360, 703; 1992). But CEA is convinced that it can persuade the government and utility companies to back the use of fast-breeders to transmute plutonium into elements with double-figure half-lives.

Waste from nuclear reactors and dismantled weapons will generate around 180 tonnes of plutonium by 2000 , causing both security and environmental concerns. Furthermore, France imposed a 15-year moratorium on deep-storage of waste in December 1991, and its management has therefore become a national priority.

CEA's new programme is called CAPRA (Consommation Accrue de Plutonium dans les Rapides). Its first phase, which will finish at the end of 1994, will assess the economics, safety and technical feasibility of a plutonium furnace. CEA will then decide whether to convert its 1,200-MW Superphénix fast-breeder reactor, at CreyMalville near Lyon, into a prototype for a purpose-built furnace.

The government, however, must first agree to restart Superphénix, which it closed in 1987 following repeated leaks in the liquid-sodium cooling circuits. The deci-

\section{US plans to abandon Delaney Clause}

Washington. The Clinton administration has proposed to abandon the 35-year-old Delaney Clause or "zero-risk standard" which governs the regulation of certain pesticide residues that concentrate in processed food or are added in food processing, and replace it with a uniform health-based safety standard that would apply equally to raw and processed foods and that would give no consideration to benefits. Under this new standard, pesticides would be judged as safe if there is "reasonable certainty of no harm"- the quantitative benchmark for which would be an upper risk estimate of one cancer case per million people over a lifetime.

The proposal is contained in a set of initiatives unveiled by the administration last week to improve the regulation of pesticides and raise public confidence in the food supply. The reform package, which would call for changes to both pesticide and food quality legislation, was presented to Congress by top officials from the Environmental Protection Agency (EPA), Food and Drug and Administration and the Department of Agriculture.

"The need for change is urgent", said EPA Administrator, Carol M. Browner. Of the 600 pesticides that are now in use in the United States, Browner said that two-thirds have never been subjected to any health standard. One senior administration official described the current system of regulation as a "mishmash of competing and conflicting standards".

The administration's proposals have already come under heavy criticism from some environmental groups who see it as a softening of the current health standards regarding pesticide residues. Nevertheless, administration officials hope they can fashion a compromise bill with lawmakers that brings together elements of two bills that have already been introduced into Congress.

One of the most controversial parts of the plan is the move to replace the Delaney Clause, which forbids the presence in food of any additive (including pesticide residues) that can be shown to cause cancer in laboratory animals. The administration now feels that, because of subsequent scientific developments, the Clause has become an anachronism, and that it should be replaced by a uniform standard of "negligible risk" applied to all pesticide residues in all foods, no matter whether the foods are marketed in raw or processed form.

At present, the Delaney Clause prohibits the approval of any pesticide that has been found to induce cancer in humans or animals if residues of the pesticide are found in processed foods above the level allowed in the raw agricultural commodity. Under these circumstances, approval is automatically denied without analysis of whether the level of risk is acceptable.

Diane Gershon

\section{University head takes over at RIKEN}

Tokyo. Akito Arima, the reform-minded former president of Tokyo University, is to replace Minoru Oda as president of the Institute of Physical and Chemical Research (RIKEN), one of Japan's foremost government research organizations, which is funded through the Science and Technology Agency.

Before taking up his position at RIKEN in 1988 , Oda - who is retiring from the post this week - headed the Institute of Space and Astronautical Science (ISAS). He and Arima have been agents of change. Both have taken the unusual step of initiating 1993). programme. near future. sion is due to be taken next year. Saving Superphénix is CEA's immediate goal. Last year, Hubert Curien, the then research minister, proposed in a report to the prime minister that the reactor be turned into a furnace. The new government is said to be impressed by Curien's conclusions.

Furnaces share the same basic design as plutonium breeders: a core of plutonium/ uranium fuel coupled with a liquid-sodium cooling system. A breeder reactor produces more plutonium than it uses, because the fast neutrons it produces transmute a blanket of nonfissile uranium surrounding its core into fissile plutonium-239. Leave out the blanket, and it consumes plutonium.

CEA plans to equip Superphénix with cores lacking the uranium blanket in 1995 and 1999. Research will then centre on raising by a factor of at least three the estimated maximum rate at which fast-breeders now consume plutonium $(25 \mathrm{~kg}$ per billion KW of electricity). A reactor of 1,200 1,500 MW could then burn 700 to $800 \mathrm{~kg}$ annually, says CEA.

Over the next 30 years, CEA proposes building one furnace for every five waterpressurized reactors in France, claiming that this would stabilize or even reduce plutonium stocks. Bouchard says CEA will also study how best to incinerate other actinide wastes, such as neptunium-237 and americium-241. He also hints that CEA might abandon oxide-based fuels in favour of metal fuels that are easier to process.

Meanwhile the US Congress is split over whether to support still a similar programme which would make use of the last remaining fast reactor in the United States - the Integral Fast Reactor in Idaho - for studies of plutonium recycling (see Nature 365, 99;

The Senate has supported a proposal from the Department of Energy to keep the reactor open for a further ${ }_{\text {: }}$ ve years in order to allow such experiments to be carried out. However, the House of Representatives has so far refused to vote any funds for such a

Declan Butler

external reviews of their organizations; such initiatives are likely to continue after this week's transition at RIKEN.

Oda and Arima are old friends from Tokyo University's Institute for Nuclear Study, where they were both based in the 1950 s. Oda will continue to serve as chairman of the board at ISAS and the National Astronomical Observatory. The space institute's director-general, Ryoji Akiba, backed by its board, is planning to launch an external review of the activities of ISAS in the

David Swinbanks 